\title{
Intraneural lipoma of the radial nerve presenting as Wartenberg syndrome: A case report and review of literature
}

\author{
Chenicheri Balakrishnan MD, Rebecca C Bachusz MD, Anila Balakrishnan BS, \\ David Elliot BS, Daniel Careaga MD
}

C Balakrishnan, RC Bachusz, A Balakrishnan, D Elliot, D Careaga. Intraneural lipoma of the radial nerve presenting as Wartenberg syndrome: A case report and review of literature. Can J Plast Surg 2009;17(4):e39-e41.

The superficial branch of the radial nerve is highly vulnerable to trauma, irritation and compression due to its anatomical location. Intraneural lipomas and fibrolipomas arising from the supporting tissues of this peripheral nerve can cause compression of the adjacent nerve leading to symptoms of neuritis of the radial nerve or Wartenberg syndrome.

Key Words: Intraneural lipoma; Wartenberg syndrome

\section{Un lipome intraneural du nerf radial se manifestant sous forme de syndrome de Wartenberg : Un rapport de cas et une analyse bibliographique}

Le rameau superficiel du nerf radial est très vulnérable aux traumatismes, à l'irritation et à la compression en raison de son foyer anatomique. Les lipomes et fibrolipomes intraneuraux émergeant des tissus de soutien de ce nerf périphérique peuvent provoquer une compression du nerf adjacent et entraîner des symptômes de névrite du nerf radial, ou syndrome de Wartenberg.
L ipomas arising in the peripheral nerves are rare tumours, with most arising in the forearm and wrist. Intraneural lipomas and lipofibromas of peripheral nerves usually present as asymptomatic swelling. As the lesions enlarge, they may cause symptoms due to progressive compression of the adjacent nerves. Significant differences are present between the wellencapsulated intraneural lipomas and the diffusely infiltrative lipofibromatous hamartoma type of intraneural lipomas. The encapsulated type tend to occur in the forth and fifth decade, with female predominance. The diffusely infiltrative type arises in a younger age group, with no sexual predominance. Intraneural lipomas are usually well encapsulated, and complete excision can be achieved without damage to the adjoining nerve. Most commonly, these tumours tend to occur within the median nerve. Lipofibromatous hamartomas of the radial nerve are exceedingly rare. Due to its rare occurrence, we report a case of intraneural lipoma of the radial nerve in the distal forearm presenting as Wartenberg syndrome.

\section{CASE PRESENTATION}

A 71-year-old man presented with a progressive swelling of his distal right forearm over a two-year period. He started noticing tingling of his hand and was given a brace for carpal tunnel syndrome by his family physician. Because the brace made the symptoms worse, he had an electromyogram and nerve conduction studies that showed no evidence of carpal tunnel syndrome. During the next few months he noticed a swelling of the forearm and was referred to us with a clinical diagnosis of ganglion cyst. His past history was significant for hypertension and hypercholesterolemia.

On examination, there was diffuse swelling of the distal forearm measuring $2 \mathrm{~cm} \times 1 \mathrm{~cm}$ (Figure 1). There was tenderness

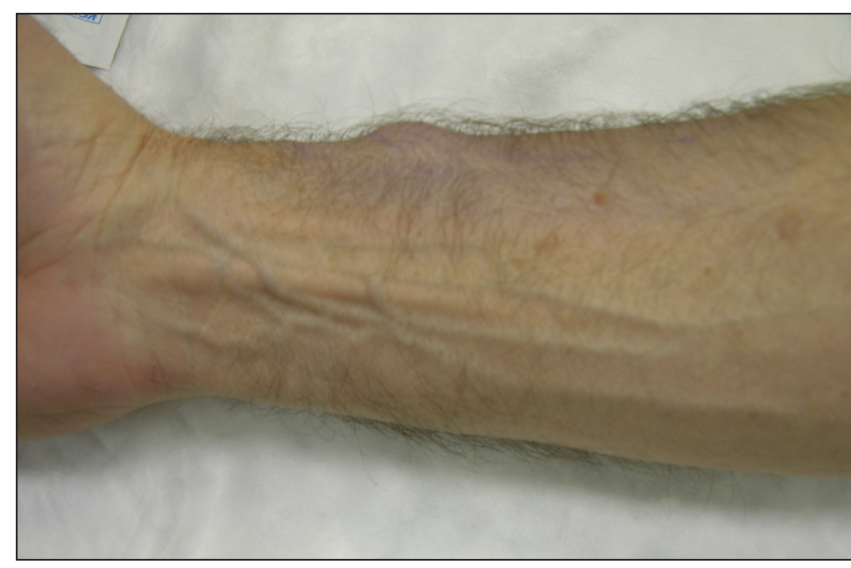

Figure 1) Swelling of the forearm

on palpation. This was not compressible and a bruit could not be heard over the swelling. An electromyogram and nerve conduction studies demonstrated slowing of conduction with sensory hyperesthesia of the radial nerve with normal median nerve and muscle function of the hand. Radiological examinations of the wrist and forearm were within normal limits.

At exploration (Figure 2), there was a well-encapsulated lipoma with the superficial branch of the radial nerve adherent to it. The lipoma was enucleated without damage to the superficial branch of the radial nerve. He had full sensory function postoperatively with no evidence of neuroma.

\section{DISCUSSION}

Nerve compression syndromes are a common cause of pain, sensory disturbance, and motor weakness in both the upper and 


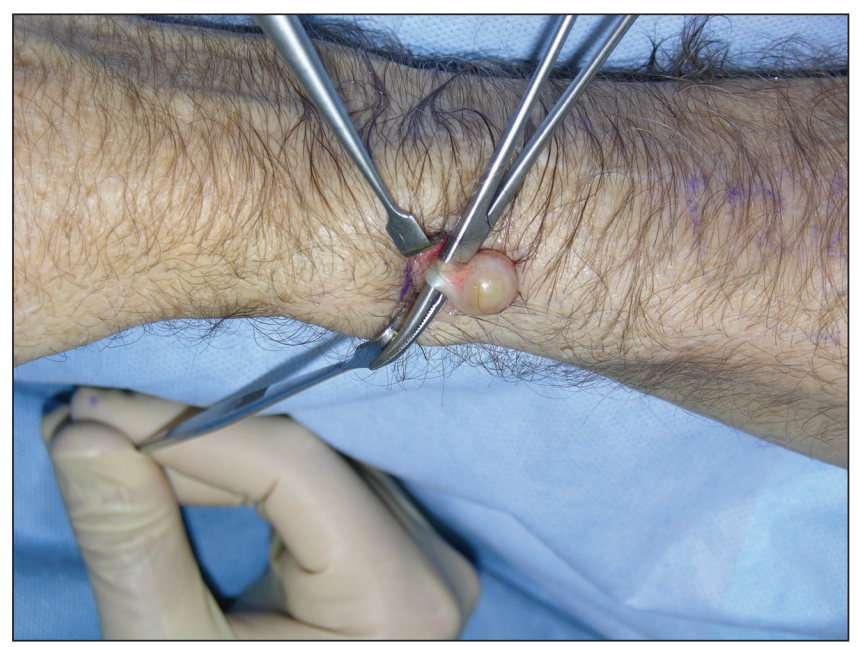

Figure 2) A well-encapsulated lipoma with the superficial branch of the radial nerve adherent to it at exploration

the lower extremities. The superficial branch of the radial nerve is highly vulnerable to trauma, irritation and compression. The superficial radial nerve exits between the brachioradialis and the extensor carpi radialis longus tendons at the junction of the proximal two-thirds to distal one-third of the forearm. The superficial radial nerve then courses in a superficial subcutaneous plane to provide sensation to the dorsal aspect of the hand from the thumb to the junction of the ring and long fingers. Sensation to the digits is provided up to the area of approximately the dorsal proximal interphalangeal joint. Compression usually occurs at the fascial bands in the subcutaneous plane between the tendons of the brachioradialis, and the extensor carpi radialis longus tendons. Understanding the anatomy of the major peripheral nerves with respect to intermuscular septa, fibrous bands, muscle margins and internervous planes is crucial to understanding how and where peripheral nerve compression can occur $(1,2)$. Wartenberg described the signs and symptoms of peripheral nerve disease of the upper extremity (3).

Peripheral nerve tumours are rare and most nerve tumours do not arise from nerve per se, but from supporting cells. These tumours are slow growing and asymptomatic, making differentiation from other soft tissue neoplasm difficult. As the lesions enlarge, symptoms of compression of the adjoining nerves may manifest. Pathological lesions include neurilemmomas, arising from the neural sheath, and centrally placed neurofibroma with nerve fibres traversing the tumour mass. Nerve tumours, which are intraneural in location but non-neural in origin, include fibrofatty infiltrate, intraneural lipomas, hemangiomas and ganglion cysts. Although well-encapsulated intraneural

\section{REFERENCES}

1. Lubahn JD, Cermak MB. Uncommon nerve compression syndromes of the upper extremity. J Am Acad Orthop Surg 1998;6:378-86.

2. Robson AJ, See MS, Ellis H. Applied anatomy of the superficial branch of the radial nerve. Clin Anat 2008;21:38-45.

3. Wartenberg R. Studies in reflexes, history, physiology, synthesis, nomenclature. Arch Neurol Psychiatry 1944;51:113-33.

4. Chiao HC, Marks KE, Bauer TW, Pflanze W. Intraneural lipoma of the sciatic nerve. Clin Orthop Relat Res 1987;221:267-71.

5. Abu Jamra FN, Rebeiz JJ. Lipofibroma of the median nerve. J Hand Surg 1979;4:160-3.

6. Camilleri IG, Milner RH. Intraneural lipofibroma of the median nerve. J Hand Surg (Br) 1998;23:120-2. lipomas have been reported within the sciatic nerve (4), most lesions are lipofibromatous hamartomas. The most common site for lipofibromatous hamartomas is the median nerve $(5,6)$. Lipofibromatous hamartomas of the radial nerve are exceedingly rare and only a few cases are reported in literature (7).

The etiology of lipofibromatous hamartomas is unknown. No specific genes have been identified as contributing to this benign perineural fibrofatty overgrowth. The disease most commonly involves the median nerve and its distribution. Lipofibromatous hamartomas may be associated with rare congenital syndromes (8). Lipomas of the hypothenar region and Guyon's canal presenting as compression neuropathy of the ulnar nerve have been reported. These slow-growing tumours present as asymptomatic swelling and diagnosis is usually made at the time of exploration. In most cases, these tumours can be enucleated without damage to the nerve fibres. (9-12) Rarely, this may present as paralysis of the intrinsic muscles of the hand (13). Although the etiology is still unclear, the suspected histiogenesis of these tumours is proliferation of the fat cells and fibroblasts of the epineurium. Pathology will show fibrofatty infiltration around the nerve fascicles that separates and compresses the nerve fascicles. This leads to atrophy of neural elements (14). All reports recommend excision or decompression of all symptomatic lesions $(15,16)$.

Lipofibromatous hamartoma of a nerve is a gross enlargement of the nerve caused by large proportions of fat and fibrous tissue, with epineural and perineural proliferation. The mass is usually slow-growing and may cause nerve compression resulting in sensory change, pain and loss of motor function. Treatment of lipofibromatous hamartoma is controversial. Recommendations include decompression and debulking of the fibrofatty sheath, microsurgical dissection of the neural elements, excision of the involved nerve segment with or without nerve grafting, and observation for asymptomatic patients. This rational surgical approach will avoid unnecessary radical nerve excision with resultant total nerve and sensory deficit (17). Treatment should be focused on alleviating the patients' symptoms and complete excision of these tumours is not recommended if clinically significant motor or sensory deficits are anticipated (18). This will preserve function of the extremity with relief of symptoms.

Our patient presented with a slow-growing tumour of the distal forearm with symptoms of sensory neuropathy of the hand. Electromyography and nerve conduction studies confirmed the sensory deficit of the radial nerve with no other abnormality. Because the lesion was confined to the superficial branch of the radial nerve, surgical exploration was carried out. Surgical enucleation of the lipoma resulted in full recovery from the sensory symptoms.

7. Herrick RT, Godsil RD Jr, Widener JH. Lipofibromatous hamertoma of the radial nerve: A case report. J Hand Surg (Am) 1980;5:211-3.

8. Choi ML, Wey PD, Borah GL. Pediatric peripheral neuropathy in Proteus syndrome. Ann Plast Surg 1998; 40:40:528-32.

9. Phelan GS, Kendrick JI, Rodriguez JM. Lipoma of the upper extremity causing nerve compression. Am J Surg 1971; 21:298-306.

10. Galeano M, Colonna M, Ristango G. Ulnar tunnel syndrome secondary to lipoma of the hypothenar region. Ann Plast Surg 2001;46:83-4.

11. Zahrawi F. Acute compression neuropathy of Guyon's canal resulting from lipoma. J Hand Surg (Am) 1984;9:238-9. 
12. McFarland GB Jr, Hoffer MM. Paralysis of the intrinsic muscle of the hand secondary to lipoma in Guyon's tunnel. J Bone Joint Surg Am 1971;53:375-6.

13. Balakrishnan C, Saini MS, DeMercurio J. Intraneural lipoma of the ulnar nerve: A case report and review of literature. Can J Plast Surg 2006;14:49-50.

14. Jacob R. Lipofibroma of the superficial branch of the radial nerve. J Hand Surg 1989;14:704-5.
15. Strickland JW, Steichen JB. Nerve tumors of the hand and forearm. J Hand Surg 1977;2:285-91.

16. Rusko RA, Larson RD. Intraneural lipoma of the median nerve case report and literature review. J Hand Surg (Am) 1981;6:388-91.

17. Terzis JK, Danel RK, Williams HB, Spencer PS. Benign fatty tumors of the peripheral nerves. Ann Plast Surg 1978;1:193-216.

18. Razzaghi A. Lipofibromatous hamartoma: Review of early diagnosis and treatment. Can J Surg 2005;48:394-9. 